\title{
Parents' quality of life and respiratory symptoms in young children with mild wheeze
}

\author{
L.M. Osman*, A.D.G. Baxter-Jones", P.J. Helms", on behalf of the EASE study group
}

Parents' quality of life and respiratory symptoms in young children with mild wheeze. L.M. Osman, A.D.G. Baxter-Jones, P.J. Helms, on behalf of the EASE study group. (C) ERS Journals Ltd 2001.

ABSTRACT: The Paediatric Asthma Caregiver's Quality of Life Questionnaire (PACQLQ), measures the impact of child asthma symptoms on family activity (CGAct) and parental anxiety (CGEmot). It has not been validated for families of children $<7$ yrs, with wheezing illness. This study assessed the sensitivity of the PACQLQ to symptom change in 62 preschool children with wheezing illness. The median age of children was 3 yrs (range 0.8-6 yrs). At entry and 3-month follow-up, parents recorded child respiratory symptoms in a 1-month diary and completed the PACQLQ. On average, children in the study had 7 symptomatic days per month.

On entry, mothers $\leqslant 30$ yrs had worse scores than those $>30(p<0.02)$, and mothers in less affluent socioeconomic groups had worse scores than those in higher groups $(p=0.05)$. Change in symptom scores and symptom free days between entry and followup was associated with change in PACQLQ scores $(r=0.54-0.57, p<0.001)$. Thirtythree parents had absolute change in PACQLQ of $<0.5$ over three months (which has been previously defined as not being clinically significant). Compared to parents with higher PACQLQ change, parents with PACQLQ scores $<0.5$, did not differ in frequency of child symptoms or in social-demographic factors, but had better quality of life scores on entry to the study $(\mathbf{p}<\mathbf{0 . 0 1})$.

It is concluded that the Paediatric Asthma Caregiver's Quality of Life Questionnaire is sensitive to group measures of child symptom change over 3 months, among preschool children, and this supports its use as an outcome measure in clinical trials. The absolute impact of child symptoms on parent quality of life varies among parents.

Eur Respir J 2001; 17: 254-258.
* Dept of Medicine and Therapeutics and ${ }^{\#}$ Dept of Child Health, University of Aberdeen, Foresterhill, Aberdeen, Scotland, UK.

Correspondence: L.M. Osman, Chest Clinic (Clinic C), Aberdeen Royal Infirmary, Foresterhill, Aberdeen, AB25 2ZN, UK

Fax: 441224840766

Keywords: Asthma

children

quality of life

Received: February 252000

Accepted after revision September 8 2000

This study was funded by the National Health Service Health Technology Assessment Programme, UK
Successful treatment of a child's asthma/wheeze should bring benefit to the family's broader functioning and quality of life, as well as improve symptoms and clinical parameters. There is increasing interest in assessing family quality of life outcomes in clinical studies [1-3]. At least one controlled trial has found significant improvement in family and caregiver quality of life as symptoms improved in intervention children [4]. Measures of caregiver quality of life may be important in explaining health service use for children with wheezing illness, because parents' response to symptoms is likely to influence decisions to seek medical care for the child. In adult asthma it has been shown that poor quality of life of the patient, independent of symptom level [5], predicts greater use of health services [6].

The Paediatric Asthma Caregiver's Quality of Life Questionnaire (PACQLQ) is designed to measure changes in family quality of life [3]. It measures the impact of child symptoms on family activity (CGAct) and parental anxiety and emotional response to child's asthma (CGEmot) and gives a total score (CGTot) from the summation of the two subscales.

The PACQLQ was developed by JUNIPER et al. [7] with parents of children aged $>7$ yrs. In this popula- tion, change in caregiver scores on the PACQLQ correlated with change in beta $(\beta)$-agonist use and clinical ratings of asthma control in the children [3], and significantly but weakly with change in lung function. Use of the PACQLQ with parents of younger children with wheeze has not been reported.

For the present group the main clinical measure is change in frequency of daily symptoms. A valid measure of family quality of life would be expected to relate to symptom severity and frequency, and that change in symptoms would be related to change in the quality of life measure.

As part of a larger study evaluating the early prescription of inhaled steroids [3, 8] this study assessed the ability of PACQLQ scores to reflect change in asthma diary scores over 3 months, for children in primary care aged $<7 \mathrm{yrs}$, with a diagnosis of asthma/wheeze.

\section{Subjects and methods}

\section{Recruitment}

Children in the study were in the care of three urban and three mixed urban/rural primary care practices in 
Aberdeen and the North East of Scotland. Eligible infants $(n=86)$ and children aged 6 months -16 yrs were identified both retrospectively and prospectively from general practice records and were recruited over an 18 month period May 1996-November 1997. Seven subjects ( $9 \%$ of those recruited) failed to complete all three assessments and dropped out of the study. Two withdrew because the family moved out of the area and the remainder because parents were unable to attend reassessment visits; there was no evidence that these children differed in any way from the other participants. The present paper reports on the 62 children aged $\leqslant 7$ yrs.

The entry criteria were a history of wheeze commencing in the previous 12 months (at least 2 episodes) and no other known lung disease or concomitant illness. All infants and children had been diagnosed with asthma/wheeze by their primary care physician and had been prescribed a $\beta$-agonist for symptomatic control. As part of a randomized trial of early intervention with inhaled corticosteroid (ICS), 33 children had been randomized to receive ICS and 29 to remain on symptomatic therapy (as required $\beta$-agonist).

The local Research Ethics Committee gave ethical approval and all parents gave informed consent.

On entry to the study standardized questionnaires [9, 10] were used to obtain information from parents with regard to recent health status and family history; child's birth details; history of wheeze; treatments used; other atopic diseases; exposure to smoke and pets in the family home; family history of asthma and atopic disease; and the siblings asthma history. Socioeconomic status of participating families was assessed by Carstairs deprivation scores [11]. These are derived from locality indices using census data for overcrowding, male unemployment, low social class, and no car as variables and have been shown to relate to health outcomes $[12-14]$. The smoking history of parents was also established by asking which household members smoked at home.

\section{Assessment of respiratory symptoms and caregiver quality of life}

Parents were asked to complete a 31 day diary and event card for the child at entry and at 3 month assessment $[15,16]$. The diary recorded daytime and night-time symptoms score for severity 0 (best) to 5
Table 1.-Baseline characteristics

\begin{tabular}{lc}
\hline Subjects $\mathrm{n}$ & 62 \\
Child age, yrs & $3(0.8-6.9)$ \\
Male & $40(64.5)$ \\
Maternal age, yrs & $30(20-42)$ \\
Household with at least 1 smoker & $20(32.3)$ \\
Household with at least 1 furry pet & $24(38.7)$ \\
Household with deprivation score & $34(57.6)$ \\
& $25(41.7)$ \\
Physician contact in previous month & $13(21.0)$ \\
\hline
\end{tabular}

Data are presented as median (range) or $\mathrm{n}(\%)$. ${ }^{*}$ : not answered $=3$; ${ }^{\uparrow}$ : Carstairs score [17] $1-7$, best (affluent) 1 , worst (deprived) 7.

(worst), visits to family physician and visits to hospital accident and emergency clinics. A month symptom score was obtained by summing scores for each day and night, giving a possible range of $0-310$ per child per month. The number of symptom free days (giving a score of $0-31$ ) was also calculated.

At the end of the first month and third month parents completed the PACQLQ [3]. The PACQLQ measures the total impact of child symptoms (CGTot) on family activity (CGAct) and parental anxiety (CGEmot).

\section{Statistical analysis}

Comparisons between repeated measures were performed using either paired samples t-test or where appropriate the Wilcoxon two-related-samples $\mathrm{Z}$ test. Examination of trends in both reported symptoms and quality of life scores were also assessed by linear correlation. All tests were two-tailed. Statistical analysis was carried out in SPSS (SPSS Advanced Statistics version 9.0, Chicago, USA).

\section{Results}

\section{Sample}

Fifty-eight mothers and four fathers completed the questionnaires. Median age of children at entry to the study was 3 yrs. One-third of households had a smoker; another one-third had a furry pet. Approximately one in five families contacted a physician because of their child's asthma or wheeze in the first diary month (table 1).

Table 2. - Family characteristics and caregiver quality of life

\begin{tabular}{|c|c|c|c|c|c|c|}
\hline \multirow{2}{*}{ PACQLQ $^{\#}$} & \multicolumn{2}{|c|}{ Mother's age } & \multicolumn{2}{|c|}{ Smoker in household $^{+}$} & \multicolumn{2}{|c|}{ Affluence/deprivation category } \\
\hline & $\leqslant 30$ yrs & $>30 \mathrm{yrs}$ & Yes & No & $1-3$ & $4-7$ \\
\hline Subjects $n$ & 31 & 27 & 20 & 42 & 34 & 25 \\
\hline CGTot & 5.3 & 6.0 & 5.3 & 5.8 & 5.9 & 5.3 \\
\hline CGAct & 5.2 & 5.9 & 5.6 & 5.9 & 5.8 & 5.6 \\
\hline CGEmot & 5.5 & 6.1 & 5.1 & 5.7 & 6.2 & 5.5 \\
\hline
\end{tabular}

CGTot: total impact of child's symptoms; CGAct: impact of child's symptoms on family activity; CGEmot: impact of child's symptoms on parental anxiety and emotional response. ${ }^{\#}$ : all Paediatric Asthma Caregiver's Quality of Life Questionnaire (PACQLQ) total and subscale scores can range from 1 (Worst) to 7 (Best); ${ }^{\Uparrow}$ : age effect CGTot $\mathrm{p}=0.02, \mathrm{CGAct} p=0.03$, CGEmot $p=0.03 ;^{+}$: household smoker effect CGTot $p=0.09$, CGAct $p=0.08$, CGEmot $p=0.18$; \$: deprivation/affluence

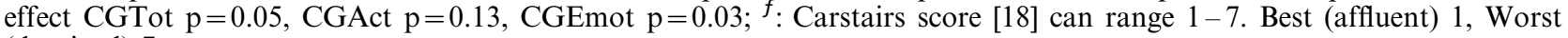
(deprived) 7 . 
Table 3. - Symptom and caregiver quality of life Month 1 and Month 3

\begin{tabular}{lcc}
\hline One month diary & Month 1 & Month 3 \\
\hline Subjects n & 60 & 56 \\
Symptom free days & $23(12.5-28)$ & $26.5(16.3-30.0)$ \\
Day symptom score & $10.0(1.0-26.3)$ & $4.0(0.0-18.8)$ \\
Night symptom score $^{-}$ & $8.0(1.0-23.0)$ & $2.0(0-11.8)$ \\
Total CGTot $^{+}$ & $6.0(5.2-6.3)$ & $6.2(5.2-6.7)$ \\
CGAct $^{\S}$ & $5.9(4.9-6.5)$ & $6.0(5.1-6.8)$ \\
CGEmot $^{f}$ & $6.0(5.3-6.6)$ & $6.2(5.6-6.7)$ \\
\hline
\end{tabular}

Data are presented as median (Interquartile range). CGTot: total impact of child's symptoms on family activity; CGEmot: impact of child's symptoms on parental anxiety and emotional response; CGAct: impact of child's symptoms on family activity. \#: symptoms were scored from 0 (none) to 5 (most severe) and summed over diary days, giving maximum score of $155 ;^{\uparrow}$ : symptoms were scored from 0 (none) to 5 (most severe) and summed over diary nights, giving maximum score of $155 ;^{+}: \mathrm{n}=62$ scored from 1 (worst) to 7 (best); ${ }^{\S}: \mathrm{n}=62$ scored from 1 (worst) to 7 (best); $f: \mathrm{n}=62$ scored from 1 (worst) to 7 (best).

Sociodemographic factors and initial Paediatric Asthma Caregiver's Quality of Life Questionnaire

Younger mothers, and those with greater social deprivation had lower (worse) PACQLQ scores. Households with a smoker had lower quality of life but the difference was not significant $(p=0.08)$ (table 2).

Child respiratory symptoms and Paediatric Asthma Caregiver's Quality of Life Questionnaire

Sixty parents completed the asthma diary in month 1 , and 56 in month 3 . Table 3 shows symptom scores and PACQLQ scores at month 1 and month 3 .

Table 4 shows Pearson (r) correlations between change in PACQLQ scores and change in symptom scores over the 3 months. All correlations were significant, but moderate. Change in symptoms explained between one-quarter and one-third of the observed variance $\left(\mathrm{r}^{2}\right)$ in PACQLQ.

Nine children had $<2$ days increase or decrease in symptom frequency. These children were defined as "stable". In this group, correlation between PACQLQ scores at 3 months and 6 months was: CGTot: $r=0.69$, $\mathrm{p}<0.05$; CGAct: $\mathrm{r}=0.51, \mathrm{p}=\mathrm{NS}$; CGEmot: $\mathrm{r}=0.80$, $\mathrm{p}<0.01$.
Sensitivity of Paediatric Asthma Caregiver's Quality of Life Questionnaire "Low responder" parents

JUNIPER et al. $[3,18]$ have defined a change of $\geqslant 0.5$ in PACQLQ scores as clinically significant. Although change in parent scores was correlated with change in PACQLQ scores, less than one-half $(29,47 \%)$ of the parents showed $\geqslant 0.5$ absolute change in their PACQLQ scores during the study. The 33 parents who showed $<0.5$ change in PACQLQ scores were defined as "low responders" (among these parents there was still significant correlation of symptom free days (and day and night scores) with each component of the PACQLQ (correlations ranged from 0.39-0.51, $\mathrm{p}<0.01)$ ).

Table 5 shows that "low responder" parents did not differ from "responder" parents in child symptom free days on entry to study (19.1 versus $19.5, \mathrm{p}=0.9)$ or change in symptom free days over the period of the study (average days improvement: 2.8 versus 2.3, $\mathrm{p}=0.9$ ). They did not differ significantly in initial symptom scores, or change in symptom scores. However, they had higher PACQLQ scores on entry to the study $(6.0$ versus $5.2, \mathrm{p}<0.01)$. Over 3 months, "responder" parents showed change of 1.4 PACQLQ points on average, compared to 0.2 for "low responder" parents.

Low responders did not differ in social characteristics such as mother's age $(\mathrm{p}=0.31)$, smoking in household $(\mathrm{p}=0.37)$, or deprivation category $(\mathrm{p}=0.98)$. Low responders also did not differ in birth order of study child $(\mathrm{p}=0.41)$ or initial birth weight $(\mathrm{p}=0.69)$.

\section{Discussion}

To be useful as an outcome measure in clinical interventions in asthma, quality of life measures must be sensitive to change in fundamental aspects of asthma. The primary aim of this study was to assess if change in child symptoms, for infants and young children with wheezing illness, was associated with change in caregiver quality of life as assessed by the Juniper PACQLQ. JUNIPER et al. [3] original validation was carried out with parents of children aged 7-17 yrs and the authors are not aware of any study which has shown that change in frequency of child symptoms is related to change in PACQLQ scores for parents of the preschool age group.

The children assessed in this study were drawn from a community sample, and probably represent the milder

Table 4. - Change in the Paediatric Asthma Caregiver's Quality of Life Questionnaire

\begin{tabular}{lccc}
\hline $\begin{array}{l}\text { Change in symptoms } \\
\text { month 1 to month 3 }\end{array}$ & $\begin{array}{c}\text { Change in caregiver } \\
\text { CGTot }\end{array}$ & $\begin{array}{c}\text { Quality of life } \\
\text { CGAct }^{\#}\end{array}$ & $\begin{array}{c}\text { Month 1 to month 3 } \\
\text { CGEmot }^{\#}\end{array}$ \\
\hline Symptom free days & $0.56(31.3)$ & $0.53(28.1)$ & $0.55(30.3)$ \\
Day symptom score & $0.54(29.2)$ & $0.54(29.2)$ & $0.50(25.0)$ \\
Night symptom score & $0.55(30.3)$ & $0.55(30.3)$ & $0.51(26.0)$ \\
\hline
\end{tabular}

Data are presented as $\mathrm{r}\left(\mathrm{r}^{2}\right)$. CGTot: total impact of child's symptoms on family activity; CGEmot: impact of child's symptoms on parental anxiety and emotional response; CGAct: impact of child's symptoms on family activity. \#: all coefficients significant at the $\mathrm{p}=0.05$ level. All correlations negative i.e. as symptom scores reduce, quality of life scores increase. 
Table 5. - Symptoms and quality of life by responder type

\begin{tabular}{|c|c|c|c|}
\hline & "Low responder" & "Responder" & p-value \\
\hline Subjects $\mathrm{n}$ & 33 & 26 & \\
\hline Initial symptom free days & $19.1 \pm 1.7$ & $19.5 \pm 2.1$ & $0.9^{\#}$ \\
\hline Initial total PACQLQ & $6.0 \pm 0.18$ & $5.2 \pm 0.18$ & $0.01^{\#}$ \\
\hline Number of children with worsening of $\geqslant 5$ symptomatic days & $5 \pm 14.7$ & $4 \pm 14.3$ & $0.97^{\bullet}$ \\
\hline Number of children with improvement of $\geqslant 5$ symptom free days & $9(\overline{30} .0)$ & $10(\overline{4} 0.0)$ & $0.44^{\star}$ \\
\hline Change in symptom free days & $2.3+9.4$ & $2.8+11.4$ & $0.86^{\oplus}$ \\
\hline Change in PACQLQ & $0.2 \pm 0.15$ & $1.4 \pm 0.72$ & $0.001^{\#}$ \\
\hline Maternal age & $30.1 \pm 5.0$ & $28.6 \pm 4.9$ & 0.31 \\
\hline Median deprivation category, mean & 2.0 & 3.0 & $0.90^{\circ}$ \\
\hline Child age & $3.8 \pm 1.5$ & $3.2 \pm 1.7$ & $0.24^{\#}$ \\
\hline First in birth order & $19(58)$ & $11(42)$ & $0.24^{\top}$ \\
\hline Birth weight $\mathrm{kg}$ & $3.3 \pm 0.71$ & $3.4 \pm 0.67$ & $0.68^{\#}$ \\
\hline
\end{tabular}

Data are presented as mean \pm SD or $\mathrm{n}(\%)$. ${ }^{\#}$ : independent samples t-test; ${ }^{\bullet}$ : Chi-squared test. PACQLQ: Paediatric Asthma Caregiver's Quality of Life Questionnaire.

end of the wheezing illness continuum. During the diary months, symptoms were recorded by parents on median 7 days. Over the 3 months symptom frequency decreased in the study group. Initial PACQLQ scores were high (indicating good quality of life). Thus, these children probably have a relatively mild level of illness. Nonetheless, it was found that change in total PACQLQ score, and in the subscales of CGAct and CGEmot was significantly related to child symptom change over 3 months. The PACQLQ appears to be sensitive to impairment in family functioning, and emotional well being of parents of preschool children even when child symptoms are relatively mild. Among the nine children who were defined as "stable" over the study period, total PACQLQ score and CGEmot score at 3 months were significantly related to scores at 6 months $(r=0.7$ and $r=0.8)$, but the correlation between CGAct at 3 and 6 months did not reach significance $(r=0.5)$. This may be due to lack of power, since numbers in the "stable" group were small. On the other hand, it may be that parents' perception of action limitation in relation to symptoms is less reliably measured over time by the PACQLQ than is emotional distress caused by symptoms.

Although correlation between change in symptoms and change in caregiver quality of life was significant, closer analysis showed that parents differed in the amount of change in their caregiver quality of life scores. JUNIPER et al. [3, 18] have suggested that a minimum change score of 0.5 is necessary to reflect clinically significant change in quality of life. When this criterion was used to identify parents who did or did not show clinically significant change in quality of life it was found that although most parents changed in PACQLQ scores as symptoms changes, some parents showed smaller absolute change in PACQLQ (i.e. $<0.5)$. It appeared that parents differed in how far the burden of care, as measured by PACQLQ, changed as symptoms changed in their child. Change in child symptoms, initial symptom level and direction of change did not differ between "low responder" and "responder" groups. But, the low responder group was significantly higher (better) in their initial PACQLQ. It seemed that from the beginning of the study some parents were more resilient to child symptoms, and these parents were less affected by change in symptoms.
What factors might explain this difference in parent resilience to child symptoms? Although younger mothers and less affluent families had overall poorer parental quality of life, age and affluence/deprivation were not significantly related to the tendency of being a "low responder" to child symptoms. Family position of the child, and child birth weight were also not significantly related to parental responder style. More general social factors, such as support network, which might play a role in family resilience were not assessed. Equally, it might be the case that a more refined measure of affluence/deprivation would show association with parent response to child symptoms.

Although a change of $\geqslant 0.5$ in PACQLQ to define responders (since it was suggested by JUNIPER et al. [3] to be the threshold of clinically significant change), the validity of such an approach cannot be confirmed by a single exploratory study of this kind. However, in the absence of any other validation of this caregiver instrument the observation that some parents show good agreement between reported quality of life and symptoms and others do not raises important questions as to the different impact on parents of changing symptoms in their children.

What implications does the possible existence of this group of "low responder" parents have for the use of the PACQLQ as an outcome measure in clinical intervention trials? The concept of a "low" responder may have implications for parent action in relation to child care. For adults with asthma it has been shown that lower quality of life, independent of symptoms, predicts use of acute care [5, 6]. Are "low responder" parents less likely to seek medical help for their child's symptoms and does parental sensitivity to symptom change have any relationship to parental willingness to adhere to child therapy?

Overall, it is concluded that in this population, there was a change in parental quality of life as child symptoms improved or worsened. Despite the need for further validation the results support the use of the PACQLQ as an outcome measure for clinical interventions in trials among preschool children, with a wide range of severity of wheezing illness.

The EASE Study Group members are: A.D.G. Baxter-Jones, P.J. Helms, G. Russell, N. Sim, J. Gordon and A. Baird, Dept of Child Health, University 
of Aberdeen; A. Grant and S. Ross, Health Services Research Unit, University of Aberdeen; D.M. Reid, Dept of Medicine and Therapeutics, University of Aberdeen; S.P. Robins, Rowett Research Institute; L.D. Ritchie and R.J. Taylor, Dept of General Practice and Primary Care, University of Aberdeen; J.A. Cairns, Health Economics Research Unit, University of Aberdeen; M.E. Fletcher, South Bank University, London.

Acknowledgements. The study was funded by the NHS Executive Health Technology Assessment Programme but the views and opinions expressed herein do not necessarily reflect the views of the NHS Executive. The authors would like to thank the patients and staff of the 6 General Practices who participated in this study: Elmbank Group Practice, NorthfieldMastrick Medical Practice and Scotstown Medical Practice, Aberdeen; Peterhead Health Centre; Inverurie Medical Group; Portlethen Health Centre.

\section{References}

1. Schulz RM, Dye J, Jolicoeur L, Cafferty T, Watson J. Quality-of-life factors for parents of children with asthma. J Asthma 1994; 31: 209-219.

2. Osman L, Silverman M. Measuring quality of life for young children with asthma and their families. Eur Respir J 1996; 21: 35s-41s.

3. Juniper EF, Guyatt GH, Feeny DH, Ferrie PJ, Griffith LE, Townsend M. Measuring quality of life in the parents of children with asthma. Quality of Life Res 1996; 5: $27-34$.

4. Mahajan P, Pearlman D, Okamoto L. The effect of fluticasone propionate on functional status and sleep in children with asthma and on the quality of life of their parents. J Allergy Clin Immunol 1998; 102: $19-$ 23.

5. Osman LM, Calder CC, Robertson R, Friend JAR, Legge JS, Douglas JG. Symptoms, quality of life and health service contact among young adults with mild asthma. Am J Respir Crit Care Med 2000; 161: 498 503.

6. van den Boom G, Rutten-van Molken MP, Tirimanna PR, van Schayck CP, Folgering $H$, van Weel $C$. Association between health-related quality of life and consultation for respiratory symptoms: results from the DIMCA programme. Eur Respir J 1998; 11: 67 72.

7. Juniper EF, Guyatt GH, Feeny DH, Ferrie PJ, Griffith LE, Townsend M. Measuring quality of life in children with asthma. Quality of Life Res 1996; 5: 35-46.

8. Baxter-Jones ADJ, Helms PJ, on behalf of The EASE Study Group. Early introduction of inhaled steroids in wheezing children presenting in primary care. A pilot study. Clin Exp Allergy 2000; 30: 1619-1626.

9. Asher MI, Keil U, Anderson HR, et al. International Study of Asthma and Allergies in Childhood (ISAAC): rationale and methods. Eur Respir J 1995; 8: 483-491.

10. de Gooijer A, Brand PL, Gerritsen J, et al. Changes in respiratory symptoms and airway hyperresponsiveness after 27 years in a population-based sample of school children. Eur Respir J 1993; 6: 848-854.

11. Carstairs V, Morris R. Deprivation and health in Scotland. Aberdeen, Aberdeen University Press, 1991.

12. Bisset AF, Russell D. Grommets, tonsillectomies, and deprivation in Scotland. BMJ 1994; 308: 1129-1132.

13. Jones CM, Woods K, Taylor GO. Social deprivation and tooth decay in Scottish schoolchildren. Hlth Bull 1997; 55: $11-15$.

14. Martuzzi M, Grundy C, Elliott P. Perinatal mortality in an English health region: geographical distribution and association with socio-economic factors. Paediat Perinat Epidem 1998; 12: 263-276.

15. Sly PD, Landau LI. Diurnal variation in bronchial responsiveness in asthmatic children. Ped Pulmonol 1986; 2: $344-352$.

16. Samet JM. Epidemiologic approaches for the identification of asthma. Chest 1987; 91: 74S-78S.

17. McLoone P. Carstairs Scores for Scottish Postcode Sectors from the 1991 Census. University of Glasgow, Glasgow, 1994.

18. Juniper EF, Guyatt GH, Willan A, Griffith LE. Determining a minimal important change in a diseasespecific quality of life questionnaire. J Clin Epidem 1994; 47: $81-87$. 